\title{
ANALISIS LITERASI KEUANGAN PADA PELAKU USAHA MIKRO DI KOTA PEKANBARU
}

\section{ANALYSIS OF FINANCIAL LITERACY FOR MICRO BUSINESS IN PEKANBARU}

\author{
Susie Suryani ${ }^{1}$ dan Surya Ramadhan ${ }^{2}$
}

Fakultas Ekonomi, Universitas Islam Riau ${ }^{1,2}$

$\underline{\text { susie@eco.uir.ac.id }}{ }^{1}, \underline{\text { uyak.ramadhan@ gmail.com }}{ }^{2}$

\begin{abstract}
This study aims to determine the level of financial literacy forMicro, Small and Medium Enterprises (MSMEs) in Pekanbaru. Besides that, this research conducted to analyzewhether the differences in gender, age, education level, and income level has significant effect towards financial literacy level for businesses. The focus of business type in this researchis trade sector that contained the number of 292 businesses as sample. The method used is survey by obtaining data through questionnaires. The results showed that the level of SMEs's financial literacyis moderate (57,9\%). Variables that affect the level of financial literacy businesses are differences in education and income. While gender and age differences has no effectto the level of MSMEs's financial literacy.
\end{abstract}

Keywords : Financial Literation, Gender, Age, Education, Income

\begin{abstract}
ABSTRAK
Penelitian ini bertujuan untuk mengetahui tingkat literasi keuangan pelaku usaha mikro kecil dan menengah (UMKM) di Pekanbaru. Disamping itu, penelitian ini juga dilakukan untuk menganalisis apakah perbedaan gender, usia, tingkat pendidikan, dan tingkat pendapatan berpengaruh signifikan terhadap tingkat literasi keuangan para pelaku usaha. Fokus jenis usaha yang diteliti adalah usaha perdagangan, dengan jumlah sampel 292 pelaku usaha. Metode penelitian yang digunakan adalah metode survey dengan cara memperoleh data melalui kuesioner. Hasil penelitian menunjukkan bahwa tingkat literasi keuangan pelaku UMKM adalah sedang (57,9\%). Variabel yang mempengaruhi tingkat literasi keuangan pelaku usaha adalah perbedaan pendidikan dan pendapatan. Sedangkan perbedaan gender dan usia tidak berpengaruh terhadap tingkat literasi keuangan para pelaku UMKM.
\end{abstract}

Kata Kunci : Literasi Keuangan, gender, usia, pendidikan, pendapatan 


\section{PENDAHULUAN}

Dalam beberapa tahun belakangan ini, di berbagai belahan dunia isu mengenai literasi keuangan (financial literacy) tengah hangat diperbincangkan. Perhatian khusus terhadap literasi keuangan di akibatkan oleh keinginan sebuah negara untuk memiliki penduduk yang berkualitas dan memiliki kecerdasan finansial yang baik, sehingga akan berdampak pada perbaikan roda ekonomi negara itu sendiri.

Literasi keuangan (Financial Literacy) dapat diartikan sebagai pengetahuan keuangan dengan tujuan untuk mencapai kesejahteraan (Lusardi, Annamaria \& Olivia S Mitchell, 2007). Literasi keuangan ini berkaitan dengan kemampuan seseorang dalam mengelola dan melakukan perencanaan terhadap keuangan. Menurut Otoritas Jasa Keuangan (OJK) perencanaan keuangan adalah tentang bagaimana cara menjalani hidup hari ini yang sederhana sesuai dengan kemampuan keuangan dan sementara itu mempersiapkan masa depan yang sejahtera. Ketidakpahaman akan pentingnya literasi keuangan dapat mengakibatkan kurangnya akses ke lembaga keuangan sehingga mudah dipengaruhi oleh penjual produk keuangan, hal tersebut tentunya dapat menghambat dalam pembangunan ekonomi negara.

Kenyataannya di kehidupan seharihari, tidak semua orang memiliki pengetahuan keuangan yang cukup atau dikatakan well literate. Beberapa penelitian menemukan bahwa tingkat literasi keuangan masyarakat secara umummasih rendah (Lusardi, Annamaria \& Olivia S Mitchell, 2007).

Berdasarkan penelitian terakhir yang dilakukan oleh MasterCard (www.mastercard.com), indeks literasi keuangan Indonesia masih rendah. Berdasarkan hasil penelitian yang dilakukan oleh MasterCard (2013),
Indonesia menduduki peringkat ke-14 dan tertinggal jauh dengan Malaysia yang menduduki peringkat ke-6. Indonesia sendiri melakukan penelitian untuk mengetahui tingkat literasi keuangan di kalangan masyarakatnya melalui OJK. Survei nasional literasi keuangan yang dilakukan OJK pada tahun 2013 menunjukkan bahwa hanya $21,84 \%$ atau seperlima dari penduduk Indonesia yang sudah terkategori well literate.

Subjek penelitian ini adalah para pelaku usaha mikro,kecil dan menengah (UMKM) khususnya para pelaku UMKM yang ada di kota Pekanbaru Riau. UMKM dipilih karena mayoritas pelaku usaha di Indonesia adalah UMKM. Sayangnya perkembangan finansial UMKM ini tergolong lambat, padahal kesuksesan mereka akan berdampak tidak hanya bagi kemajuan usaha mereka sediri tetapi juga dapat mengurangi pengangguran dan dapat meningkatkan pendapatan daerah maupun pendapatan nasional. Hal ini dikarenakan berdasarkan beberapa penelitian tentang pelaku usaha masih ditemukan rendahnya tingkat literasi keuangan di kalangan para pelaku usaha. Kurangnya literasi keuangan akan menyebabkan seseorang lebih cenderung memiliki masalah dengan hutang, terlibat dengan biaya kredit yang lebih tinggi dan kecil kemungkinannya untuk merencanakan masa depan (Lusardi, 2010)

Penelitian yang dilakukan oleh Hawati Janor, Rubayah Yakob, Noor Azuan Hashim, Zanariah dan Che Aniza Che Wei (Faculty of Economic and Management University Kebangsaan Malaysia) menyimpulkan bahwa faktor demografi, ekonomi,sosial dan faktor phsikologis merupakan faktor utama financial literacy yang berhubungan 
dengan keputusan pelaku usaha untuk berinvestasi.

Sementara itu hasil penelitian Risky Amaliyah dan Rini Setyo Wati (2015), tentang faktor mempengaruhi tingkat literasi keuangan di kalangan pelaku usaha keil dan menengah (UMKM) kota Tegal" menemukan bahwa tingkat literasi keuangan para pelaku UMKM kota Tegal masih rendah, dengan faktor yang mempengaruhi literasi keuangan terdiri dari gender,tingkat pendidikan dan tingkat pendapatan pelaku usaha.

Tasya Desiyana (2015) dalam penelitiannya tentang tingkat literasi keuangan pada pelaku usaha mikro kecil dan menengah (UMKM) di daerah istimewa Yokyakarta menemukan bahwa tingkat literasi keuangan pelaku UMKM kota istimewa Yokyakarta berada pada kategori sedang. Hasil penelitian juga menyimpulkan bahwa terdapat perbedaan pengetahuan literasi keuangan para pelaku UMKM berdasarkan perbedaan jenis kelamin.

Penelitian ini ingin melihat bagaimanakah tingkat literasi keuangan para pelaku UMKM dan apakah perbedaan gender, usia, tingkat pendidikan, dan tingkat pendapatan berpengaruh terhadap literasi keuangan para pelaku UMKM di kota Pekanbaru.

Menurut Jump Star Coalition (dalam Huston, 2010) "Literasi keuangan adalah pengetahuan untuk menggunakan keterampilan dan pengetahuan untuk mengelola sumber keuangan secara efektif untuk keamanan financial seumur hidup."

Studi menilai literasi keuangan investor UEA individu yang berinvestasi di pasar keuangan lokal. Ini juga menguji pengaruh faktor demografi terhadap literasi keuangan, khususnya usia, jenis kelamin, pendidikan, dan pendapatan bulanan.
Menurut Chen, $\mathrm{H}$ and Volpe, $\mathrm{R}$ (1998) dari hasil penelitian di 13 kampus di USA dengan 924 sampel menunjukkan bahwa tingkat literasi keuangan berkaitan dengan gender, usia, nasionalsme, ras, penghasilan, pengalaman kerja, disiplin akademis, and peringkat.

Organisation for Economic Cooperation and Development, 2005 (OECD) adalah bahwa, ini adalah kombinasi antara kesadaran, pengetahuan, sikap dan perilaku yang diperlukan untuk menghasilkan keputusan keuangan yang baik dan padaakhirnya mencapaikesejahteraan finansial individu.

Selain berfokus pada tingkat Literasi keuangan, studi di daerah tersebut juga meneliti faktor-faktor yang mempengaruhi tingkat. Misalnya, dengan menggunakan data AS, Hogarth J.M. (2002), mengeksplorasi Literasi Keuangan orang dewasa mengenai topik yang terkait dengan keuangan pribadi.

Studi tersebut menunjukkan bahwa, secara umum, responden berpengetahuan kurang berpeluang lebih cenderung berpendidikan tunggal, berpengetahuan rendah, berpenghasilan rendah, minoritas, dan berusia muda atau tua (bukan setengah baya). Studi menggunakan data Beal, D.J. \& Delpachtra, S.B. (2003), mengukur Literasi Keuangan siswa Australia dan menemukan bahwa mahasiswanya tidak terampil dan tidak berpengetahuan luas dalam masalah keuangan. Di luar tingkat ini, mereka menemukan bahwa siswa dengan nilai lebih tinggi cenderung menjadi laki-laki, memiliki pengalaman kerja lebih besar dan memiliki pendapatan lebih tinggi. Studi oleh Andreq C. Worthington (2006) di Australia juga, menggunakan model regresi logit untuk memprediksi orang dewasa literasi keuangan dari orang Australia. Hasil penelitian menunjukkan 
bahwa literasi keuangan ditemukan paling tinggi untuk orang berusia antara 60 dan 60 tahun, profesional, bisnis dan pemilik peternakan. Literasi keuangan adalah yang terendah untuk pengangguran, wanita dan orang-orang dari latar belakang non-Inggris.

Lusardi dan Mitchell (2009) memotret fenomena ini dalam penelitiannya mengenai kompleksitas pengambilan keputusan ekonomi yang menitikberatkan pada kepemilikan pengetahuan mengenai keuangan akan mendorong keberhasilan usaha dan kesiapan menghadapi masa pensiun. Selanjutnya juga ia membagi variabel kepemilikan pengetahuan keuangan yang selanjutnya disebut financial literacy menjadi 2 tahap, yaitu tahap dasar dan tahap lanjutan.

Indikator literasi keuangan tahap dasar meliputi pengetahuan mengenai perhitungan matematika, tingkat suku bunga, inflasi, nilai waktu uang dan tipuan nilai uang. Sedangkan literasi keuangan tahap lanjutan meliputi pengetahuan tetang pasar saham dan fungsinya, reksadana, tingkat suku bunga acuan dan keterkaitannya dengan obligasi, perusahaan pengelola keuangan, pengetahuan tentang risikorisiko finansial apabla menginvestasikan uangnya pada berbagai pilihan investasi saham atau obligasi, tingkat pengembalian uang jangka panjang, fluktuasi atau ketidakpastian yang tinggi, dan diversifikasi risiko.

Menurut Oseifuah, Emmanuel Kojo (2010), ada 3 indikator Financial Literacy, antara lain :

\section{Financial Knowledge memilikipengetahuanmengenai terminologi-terminologikeuangan.}

2. Financial Attitudes : ketertarikan atau minat dalam memperbaiki pengetahuan keuangan.

3. Financial Behaviour : berorientasi untuk spending dan saving.
Menurut Otoritas Jasa Keuangan dalam surat edaran OJK 2014 menyatakan bahwa literasi keuangan adalah rangkaian proses atau aktivitas untuk meningkatkan pengetahuan, keyakinan, dan keterampilan konsumen dan masyarakat luas sehingga mereka mampu mengelola keuangan dengan lebih baik. Adanya literasi keuangan bertujuan untuk meniadakan segala bentuk hambatan yang bersifat harga maupun non-harga, terhadap akses masyarakat dalam memanfaatkan layanan jasa keuangan. OJK memiliki program guna meningkatkan indeks literasi keuangan di Indonesia dalam bentuk Strategi Nasional Literasi Keuangan Indonesia (SNLKI). Kerangkan dasar SLNKI terdiri atas tiga pilar yaitu : (1) Edukasi dan Kampanye Nasional Literasi Keuangan, (2) Penguatan Infrastruktur Literasi Keuangan, dan (3) Pengembangan Produk dan Jasa Keuangan.

Tingkat literasi keuangan yang dimiliki setiap individu tentunya berbeda-beda. Hal tersebut disebabkan oleh perbedaan faktor yang mempengaruhinya sehingga terjadi perbedaan yang signifikan antara individu satu dengan individu lainnya.
1. Perilaku
Keuangan
(Financial
Behavior)

FinancialBehavior berhubungan dengan tanggung jawab keuangan seseorang terkait dengan cara pengelolaan keuangan. Menurut Hilgert, Jeanne and Sandra (2003), menyebutkan bahwa perilaku keuangan seseorang akan tampak dari seberapa bagus seseorang mengelola uang kas, mengelola utang, tabungan dan pengeluaran-pengeluaran lainnya.

2. Faktor Demografi

Dalam hal ini dikatakan bahwa perempuan dan etnis minoritas memiliki pengetahuan keuangan yang 
rendah, sementara menurut Monticone, Chiara (2010), menyatakan bahwa laki-laki memiliki pengetahuan keuangan dan ekonomi makro yang baik.

3. Pendidikan

Variabel pendidikan sebagai human capital merupakan salah satu variabel yang diharapkan akan memberikan efek terhadap kesejahteraan seseorang. Variabel pendidikan berpengaruh pada produktifitas dan efisiensi kerja seseorang yang kemudian akan mempengaruhi real income induvidu atau rumah tangga (Rahmatia, 2004).

4. Latar Belakang Keluarga

Selain Demografi dan kemampuan kognitif, literasi keuangan juga dilatar belakangi oleh keluarga seperti pendidikan orang tua terutama ibu. Jadi pendidikan yang diperoleh dari orang tua atau keluarga dapat mempengaruhi pengetahuan keuangan seseorang (Tasya Desiyana, 2015).

5. Jenis Kelamin

Chen dan Volpe (1998) menemukan bahwa dalam hal financial literacy pada tingkat umum perempuan lebih rendah daripada laki-laki. Hal ini. Lalonde dan Schmidt (2010) memperkuat temuan yang menyatakan bahwa literasi keuangan bentuk pengetahuan umum pada laki-laki lebih tinggi dibandingkan perempuan.

a. Pengertian UMKM

Usaha Mikro Kecil dan Menengah (UMKM) di Indonesia merupakan salah satu penggerak perekonomian rakyat yang tangguh dan mampu menunjukkan eksistensinya di dunia usaha. Menurut UU No.20 Tahun 2008 yang dimaksud Usaha Mikro Kecil dan Menengah (UMKM) :
1) Usaha Mikro adalah usaha produktif milik orang perorangan dan/atau badan usaha perorangan yang memenuhi kriteria Usaha Mikro sebagaimana diatur dalam Undang-Undang ini.

2) Usaha Kecil adalah usaha ekonomi produktif yang berdiri sendiri, yang dilakukan oleh orang perorangan atau badan usaha yang bukan merupakan anak perusahaan atau bukan cabang perusahaan yang dimiliki, dikuasai atau menjadi bagian baik langsung maupun tidak langsung dari usaha menengah atau usaha besar yang memenuhi kriteria Usaha Kecil sebagaimana dimaksud dalam Undang-Undang ini.

3) Usaha Menengah adalah usaha ekonomi produktif yang berdiri sendiri, yang dilakukan oleh orang perseorangan atau badan usaha yang bukan merupakan anak perusahaan atau cabang perusahaan yang dimiliki, dikuasai, atau menjadi bagian baik langsung maupun tidak langsungdengan Usaha Kecil atau usaha besar dengan jumlah kekayaan bersih atau hasil penjualan tahunan sebagaimana diatur dalam Undang-Undang ini.

b. Kriteria Usaha Mikro Kecil dan Menengah (UMKM)

Menurut Rahmana, Arief (2009) dalam perspektif perkembangannya kriteria Usaha Kecil dan Menengah dibagi menjadi 4 kelompok, yaitu:

1) Livelihood Activities, merupakan UKM yang digunakan sebagai kesempatan kerja untuk mencari nafkah, yang lebih umum dikenal sebagai sektor informal. Contohnya adalah pedagang kaki lima.

2) Micro Enterprise, merupakan UKM yang memiliki sifat 
pengrajin tetapi belum memiliki sifat kewirausahaan.

3) Small Dynamic Enterprise, merupakan UKM yang telah memiliki jiwa kewirausahaan dan mampu menerima pekerjaan subkontrak dan ekspor.

4) Fast Moving Enterprise, merupakam UKM yang telah memiliki jiwa kewirausahaan dan akan melakukan transformasi menjadi Usaha Besar (UB).

\section{METODE PENELITIAN}

Metode penelitian yangdigunakan dalam penelitian ini adalah metode survey dengan menggunakan kuisioner yang sudah dilakukan uji validitasnya. Selanjutnya dilakukan analisis deskriptif untuk menggambarkan tingkat literasi keuangan pelaku UMKM yang bisa dikategorikan dalam tingkat pemahaman tinggi, sedang, atau rendah. Sedangkan

$$
\begin{gathered}
\text { Interval }=\frac{\text { Nilai Tertinggi }- \text { Nilai Terindah }}{\text { Banyak Kelas }} \\
\text { Interval }=\frac{115-23}{3}=31
\end{gathered}
$$

untuk melihat apakah perbedaan gender, usia, tingkat pendidikan, dan tingkat pendapatan berpengaruh terhadap tingkat literasi keaungan pelaku UMKM digunakan analisi Chi Square.

Jumlah populasi dalam penelitian ini adalah sebanyak 6.563 UMKM. Adapun penentuan sampel adalah dengan menggunakan rumus slovin pada $\alpha=5 \%$ dan didapatkan jumlah sampel sebanyak 377. Dari jumlah tersebut yang memenuhi persyaratan untuk dianalisis adalah sebanyak 292 UMKM.

\section{HASIL DAN PEMBAHASAN}

Penelitan ini dilakukan di Kota Pekanbaru dengan objek penelitian adalah pelaku UMKM sektor perdagangan yaitu sebanyak 292 sampel.
Pada penelitian ini penulis mengambil 4 variabel untuk mengukur tingkat literasi keuangan para pelaku UMKM di kota Pekanbaru yaitu Gender, Usia, Tingkat Pendidikan, dan Tingkat Pendapatan. Berikut ini frekuensi data dari ke 4 variabel yang dapat dilihat pada tabel 1 .

\section{Tabel 1}

\begin{tabular}{|c|c|c|c|c|c|c|}
\hline Kategori & \multicolumn{2}{|c|}{ Laki-laki } & \multicolumn{2}{|c|}{ Perempuan } & & \\
\hline \multirow{2}{*}{ Gender } & Jumlah & $\%$ & Jumlah & $\%$ & & \\
\hline & 122 & 41,8 & 170 & 58,2 & & \\
\hline \multirow{3}{*}{ Usia } & \multicolumn{2}{|c|}{$20-35$ tahun } & \multicolumn{2}{|c|}{$36-50$ tahun } & \multicolumn{2}{|c|}{$>50$ tahun } \\
\hline & Jumlah & $\%$ & Jumlah & $\%$ & Jumlah & $\%$ \\
\hline & 139 & 47,6 & 128 & 43,8 & 25 & 8,6 \\
\hline \multirow{3}{*}{$\begin{array}{c}\text { Tingkat } \\
\text { Pendidikan }\end{array}$} & \multicolumn{2}{|c|}{ SMPSederajat } & \multicolumn{2}{|c|}{ SMA/Sederajat } & \multicolumn{2}{|c|}{ Sarjana } \\
\hline & Jumlah & $\%$ & Jumlah & $\%$ & Jumlah & $\%$ \\
\hline & 81 & 27,7 & 178 & 61,0 & 33 & 11,3 \\
\hline \multirow{3}{*}{$\begin{array}{c}\text { Tingkat } \\
\text { Pendapatan }\end{array}$} & \multicolumn{2}{|c|}{$1-10$ juta } & \multicolumn{2}{|c|}{ 11-20 juta } & \multicolumn{2}{|c|}{$>20$ juta } \\
\hline & Jumlah & $\%$ & Jumlah & $\%$ & Jumlah & $\%$ \\
\hline & 193 & 66,1 & 52 & 17,8 & 47 & 16,1 \\
\hline
\end{tabular}

\section{Rekapitulasi Identitas Responden}

Sumber : Data olahan, 2016

Data yang diteliti dikelompokkan ke dalam tiga kategori, yaitu tingkat literasi keuangan tinggi, sedang, danrendah, dengan menyusun interval data, sebagai berikut :

- Tinggi $=5 \times 23=115$

- Rendah $=1 \times 23=23$

Sehingga diperoleh data interval sebagai berikut :

Tabel 2

Interval Data

\begin{tabular}{cc}
\hline Interval Data & Kategori \\
\hline $115-84$ & Tinggi \\
\hline $83-52$ & Sedang \\
\hline $51-20$ & Rendah \\
\hline
\end{tabular}

Sumber : Data olahan, 2016

Dari 292 sampel tersebut dikelompokkan ke dalam tiga kelompok atau kategori berdasarkan skor tingkat literasi yang diterimanya, yaitu kelompok pemilik usaha yang memperoleh skor tingkat literasi tinggi, sedang, danrendah, dicari menggunakan crosstabulation antara tingkat literasi keuangan dengan faktor-faktor yang mempengaruhi (gender, usia, tingkat pendidikan, tingkat pendapatan, tempat 
usaha). Dapat dilihat pada tabel-tabel dibawah ini.

\section{Tabel 3}

Tingkat Literasi Keuangan * Gender Crosstabulation

\begin{tabular}{ccccc}
\hline & & \multicolumn{2}{c}{ Gender } & \\
\cline { 3 - 4 } & & Perempuan & $\begin{array}{c}\text { Laki- } \\
\text { laki }\end{array}$ & Total \\
\hline Tingkat & Rendah & 18 & 11 & 29 \\
\cline { 3 - 5 } Literasi & Sedang & 92 & 77 & 169 \\
\cline { 2 - 5 } Keuangan & Tinggi & 60 & 34 & 94 \\
\hline \multicolumn{2}{c}{ Total } & 170 & 122 & 292 \\
\hline
\end{tabular}

Sumber : Data olahan, 2016

Berdasarkan tabel diatas jika dilihat dari gender maka tingkat literasi keuangan pelaku usaha mikro di Pekanbaru termasuk dalam kategori sedang dengan perempuan sebesar 92 dan laki-laki 77.

\section{Tabel 4}

Tingkat Literasi Keuangan * Usia Crosstabulation

\begin{tabular}{c|c|c|c|c|c}
\hline \multicolumn{2}{c|}{} & \multicolumn{3}{|c|}{ Usia } & \multirow{2}{*}{ Total } \\
\cline { 2 - 6 } \multicolumn{2}{c|}{} & $20-35$ & $36-50$ & $>50$ & \\
\hline $\begin{array}{c}\text { Tingkat } \\
\text { Literasi } \\
\text { Keuangan }\end{array}$ & Rendah & 16 & 12 & 1 & 29 \\
\cline { 2 - 6 } & Sedang & 80 & 74 & 15 & 169 \\
\cline { 2 - 6 } & Tinggi & 43 & 42 & 9 & 94 \\
\hline \multicolumn{2}{c|}{ Total } & 139 & 128 & 25 & 292 \\
\hline
\end{tabular}

Sumber : Data olahan, 2016

Berdasarkan tabel diatas jika dilihat dari usia maka tingkat literasi keuangan pelaku usaha mikro di Pekanbaru termasuk dalam kategori sedang dengan usia 20-35 tahun sebesar 80 , usia 36-50 tahun sebesar 74 , dan usia $>50$ tahun sebesar 15 .

\section{Tabel 5}

Tingkat Literasi Keuangan * Tingkat

Pendidikan Crosstabulation

\begin{tabular}{cccccc}
\hline & \multicolumn{3}{c}{ Tingkat Pendidikan } & \\
\cline { 3 - 5 } & & $\begin{array}{c}\text { SMP/S } \\
\text { ederajat }\end{array}$ & $\begin{array}{c}\text { SMA/S } \\
\text { ederaja } \\
\mathrm{t}\end{array}$ & Sarjana & Total \\
\hline Tingkat & Rendah & 2 & 24 & 3 & 29 \\
\cline { 2 - 5 } $\begin{array}{c}\text { Literasi } \\
\text { Keuangan }\end{array}$ & Sedang & 52 & 95 & 22 & 169 \\
\cline { 2 - 5 } & Tinggi & 27 & 59 & 8 & 94 \\
\hline Total & 81 & 178 & 33 & 292 \\
\hline
\end{tabular}

Sumber : Data olahan, 2016

Berdasarkan tabel diatas jika dilihat dari tingkat pendidikan maka tingkat literasi keuangan pelaku usaha mikro di Pekanbaru termasuk dalam kategori sedang dengan tingkat pendidikan SMP/Sederajat sebesar 52, tingkat pendidikan SMA/Sederajat sebesar 95, dan tingkat pendidikan Sarjana sebesar 22.

\section{Tabel 6}

Tingkat Literasi Keuangan * Tingkat Pendapatan Crosstabulation

\begin{tabular}{cccccc}
\hline & & \multicolumn{3}{c}{ Tingkat Pendapatan } & \multirow{2}{*}{ Total } \\
\cline { 3 - 5 } & & $1-10 \mathrm{jt}$ & $11-20 \mathrm{jt}$ & $>20 \mathrm{jt}$ & \\
\hline Tingkat & Rendah & 26 & 1 & 2 & 29 \\
\cline { 2 - 6 } Literasi & Sedang & 113 & 29 & 27 & 169 \\
\cline { 2 - 5 } Keuangan & Tinggi & 54 & 22 & 18 & 94 \\
\hline \multicolumn{2}{c}{ Total } & 193 & 52 & 47 & 292 \\
\hline
\end{tabular}

Sumber : Data olahan, 2016

Berdasarkan tabel diatas jika dilihat dari tingkat pendapatan maka tingkat literasi keuangan pelaku usaha mikro di Pekanbaru termasuk dalam kategori sedang dengan tingkat pendapatan 1-10 juta sebesar 113, tingkat pendapatan 11-20 juta sebesar 29 , dan tingkat pendapatan $>20$ juta sebesar 27.

\section{Uji Hipotesis (Chi-Square)}

Untuk menganalisis apakah perbedaan gender, usia, tingkat pendidikan, dan tingkat pendapatanakan mempengaruhi tingkat literasi keuangan para pelaku usaha mikro dilakukan pengujian menggunakan analisis ChiSquare, sebelum melakukan analisis denganChi-Square terlebih dahulu melakukan analisis dengan menggunakan tabulasi silang (crosstab) seperti yang telah dilakukan sebelumnya pada sub bab Deskriptif Variabel Penelitian. Dari hasil tabulasi silang (crosstab), maka secara umum dapat disimpulkan bahwa tingkat literasi keuangan pelaku usaha mikro dalam penelitianini termasuk dalam kategori sedang (menengah).

\section{Tabel 7}

\section{Chi-Square Tests Literasi Keuangan} Berdasarkan Gender Asymp. Sig. Value Df (2-sided) 


\begin{tabular}{lrrr}
\hline $\begin{array}{l}\text { Pearson Chi- } \\
\text { Square }\end{array}$ & $2,387 \mathrm{a}$ & 2 &, 303 \\
\hline Likelihood Ratio & 2,399 & 2 &, 301 \\
\hline $\begin{array}{l}\text { Linear-by-Linear } \\
\text { Association }\end{array}$ &, 653 & 1 &, 419 \\
\hline N of Valid Cases & 292 & & \\
\hline Sumber : Data olahan, 2016 &
\end{tabular}

Hasil pengujian terhadap variabel bebas gender dengan tingkat literasi keuangan di kalangan pelaku usaha mikro di kota Pekanbaru diperoleh nilai signifikansi 0,303 . Nilai signifikansi tersebut lebih besar dari $(\alpha=0,05$ maupun $\alpha=0,1)$ sehingga dapat disimpulkan bahwa gender tidak berpengaruh terhadap tingkat literasi keuangan di kalangan pelaku usaha mikro di kota Pekanbaru, maka hipotesis ini ditolak. Hasil penelitian ini bertentangan dengan penelitian Chen and Volpe (1998) yang menyatakan bahwa gender berpengaruh signifikan terhadap tingkat literasi keuangan. Tidak berpengaruhnya gender terhadap literasi keuangan responden pada penelitian ini karena persentase responden yang dijadikan sampel baik pria maupun wanita hampir sama.

\section{Tabel 8}

Chi-Square Tests Literasi Keuangan Berdasarkan Usia

\begin{tabular}{lrrr}
\hline & Value & Df & \multicolumn{2}{c}{$\begin{array}{c}\text { Asymp. Sig. } \\
(2-s i d e d)\end{array}$} \\
\hline Pearson Chi-Square & $1,493 \mathrm{a}$ & 4 &, 828 \\
\hline Likelihood Ratio & 1,734 & 4 &, 785 \\
\hline $\begin{array}{l}\text { Linear-by-Linear } \\
\text { Association }\end{array}$ &, 912 & 1 &, 339 \\
\hline N of Valid Cases & 292 & & \\
\hline
\end{tabular}

Sumber : Data olahan, 2016

Hasil pengujian terhadap pengaruh perbedaanusia dengan tingkat literasi keuangan di kalangan pelaku usaha mikro di kota Pekanbaru diperoleh nilai signifikansi 0,828 . Nilai signifikansi tersebut lebih besar dari $(\alpha=$ $0,05$ maupun $\alpha=0,1)$ sehingga dapat disimpulkan bahwa perbedaanusiatidak berpengaruh signifikan terhadap tingkat literasi keuangan di kalangan pelaku usaha mikro di kota Pekanbaru,. Hasil ini bertentangan dengan penelitian $\mathrm{Al}-$ Tamimi (2009) yang menunjukkan bahwa usia mempengaruhi tingkat literasi keuangan individu, tetapi mendukung hasil penelitian Rizky Amalia dan Retni Setyawati (2015).

\section{Tabel 9}

\section{Chi-Square Tests Literasi Keuangan Berdasarkan Tingkat Pendidikan}

\begin{tabular}{lrrr}
\hline & Value & Df & $\begin{array}{c}\text { Asymp. Sig. } \\
\text { (2-sided) }\end{array}$ \\
\hline $\begin{array}{l}\text { Pearson Chi- } \\
\text { Square }\end{array}$ & $9,181 \mathrm{a}$ & 4 &, 057 \\
\hline Likelihood Ratio & 10,969 & 4 &, 027 \\
\hline $\begin{array}{l}\text { Linear-by-Linear } \\
\text { Association }\end{array}$ & 2,193 & 1 &, 139 \\
\hline N of Valid Cases & 292 & & \\
\hline
\end{tabular}

Sumber: Data olahan, 2016

Hasil pengujian terhadap variabel bebas tingkat pendidikan dengan tingkat literasi keuangan di kalangan pelaku usaha mikro di kota Pekanbaru diperoleh nilai signifikansi 0,057 . Nilai signifikansi tersebut lebih kecil dari $(\alpha=$ $0,1)$ sehingga dapat disimpulkan bahwa perbedaan tingkat pendidikan berpengaruh terhadap tingkat literasi keuangan di kalangan pelaku UMKM di kota Pekanbaru. Hasil penelitian ini sesuai dengan penelitian Jhonson dan Margareth (2007) yang menyatakan bahwa pendidikan memilik peran yang sangat penting terhadap tingkat literasi keuangan individu. Begitu juga menurut Gutter (2008), yang menyatakan bahwa pendidikan berpengaruh positif signifikan terhadap pengetahuan keuangan. Individu yang mendapatkan pendidikan keuangan yang baik dari orang tuanya dan lembaga pendidikan tempat dia dididik akan memiliki tingkat pengetahuan keuangan yang lebih baik.

Tabel 10

Chi-Square Tests Literasi Keuangan Berdasarkan Tingkat Pendapatan

\begin{tabular}{lcrr}
\hline & Value & df & $\begin{array}{c}\text { Asymp. Sig. } \\
(2 \text {-sided })\end{array}$ \\
\hline Pearson Chi-Square & $10,636 \mathrm{a}$ & 4 &, 031 \\
\hline Likelihood Ratio & 12,365 & 4 &, 015 \\
\hline
\end{tabular}




\begin{tabular}{lrrr}
\hline $\begin{array}{l}\text { Linear-by-Linear } \\
\text { Association }\end{array}$ & 6,747 & 1 &, 009 \\
\hline N of Valid Cases & 292 & & \\
\hline
\end{tabular}

N of Valid Cases 292

Sumber : Data olahan, 2016

Hasil pengujian terhadap variabel bebas tingkat pendapatan dengan tingkat literasi keuangan di kalangan pelaku usaha mikro di kota Pekanbaru diperoleh nilai signifikansi 0,031 . Nilai signifikansi tersebut lebih kecil dari $(\alpha=$ $0,05$ maupun $\alpha=0,1)$, sehingga dapat disimpulkan bahwa perbedaan tingkat pendapatan berpengaruh terhadap tingkat literasi keuangan di kalangan pelaku usaha mikro di kota Pekanbaru, maka hipotesis ini diterima. Hasil penelitian ini mendukung penelitian yang telah dilakukan oleh Lusardi, Annamaria, Olivia S. Mitchell (2011), Chen and Volpe (1998), dan Al-Tamimi (2009). Namun bertentangan dengan hasil penelitian Rizki Amalia dan Retno Setyawati (2015).

Perbedaan hasil penelitian ini dengan beberapa hasil sebelumnya disebabkan oleh adanya perbedaan daerah (lokasi penelitian), culture, adat istiadat, agama, kehidupan sosial, lingkungan tempat berusaha, regulasi daerah maupun jenis usaha yang dilakoni responden. Jika responden yang dijadikan sampel relatif homogen, maka pengaruh faktor demografi terhadap tingkat literasi keuangan pelaku usaha relatif tidak signifikan.

\section{PENUTUP \\ Kesimpulan}

Kesimpulan dari penelitian ini adalah menunjukkan tingkat literasi keuangan pelaku UMKM berada dalam kategori sedang, dan pengaruh perbedaan dari empat variabel yang diuji menunjukkan bahwa tingkat pendidikan dan pendapatan berpengaruh signifikan terhadap tingkat literasi keuangan, sedangkan gender dan usia tidak berpengaruh terhadap tingkat literasi keuangan pelaku UMKM.

\section{Saran}

Disarankan bagi yang ingin melakukan penelitian selanjutnya agar menambah variabe penelitian, memperluas subjek maupun objek penelitian. Dan diharapkan bagi agar pemerintah dapat meningkatkan sosialisasi terhadap pelaku UMKM.

\section{DAFTAR PUSTAKA}

Al-Tamimi HAH, Al-Anood K (2009) Financial Literacy and Investment Decisions of UAE Investors, The Journal of Risk Finance 10(5), 500 $-516$.

Andrew C. Worthington (2006). Predicting Financial Literacy in Australia.

Anwar Sanusi, Metodologi Penelitian Bisnis, Jakarta

Beal, D.J. \& Delpachtra, S.B. (2003). Financial literacy among Australian university students, Economic Papers, 22, 65-78.

Cahyono, Nur Edi (2012). Pentingnya Melek Finansial Bagi Pelaku Usaha Kecil dan Menengah. Pengajar Jurusan Akuntasi STIE Rajawali Purworejo. Vol 8 No 2. Diunduh pada tanggal 26/03/2016.

Capuano, Angelo dan Ian Ramsay (2011). What Causes Suboptimal Financial Behaviour? An Exploration Of Financial Literacy 
Social Influences And Behavioural Economics. Diunduh pada tanggal 26/03/2016.

Chen, H. and Volpe, R. (1998). An analysis of personal financial literacy among college students. Financial Review Service.

Gutter, M (2008). Financial Manajemen Practicesof Collage Student from States With Varying Financial Education Mandates.

Hawati Janor, Rubayah Yakob, Noor Azuan Hashim, Zanariah, Che Aniza Che Wel, Financial Literacy and Investment Decisions in Malaysia and United Kingdom : A Comparative Analysis.

Hilgert, M, Jeanne M. dan Sandra, B. (2003). Household Financial Management: The Connection Between Knowledge and Behavior. Federal Reserve Bulletin, Vol. 89, pp. 309-322.

Hogarth, J.M. (2002). Financial literacy and family and consumer sciences. Journal of Family and Consumer Sciences, 94, 15-28.

Huston, Sandra J. (2010). Measuring financial literacy. The Journal of Consumer Affairs, 44(2), 296-316. Diunduh pada tanggal 19/04/2016.

Jhonson,E \& Margaret, S.S. (2007). From Financial Literacy to Financial Capability Among The Young. Journal of Sociologi and Social Welfare, (Online), 34:119146.

Lilia Pasca Riani (2015). Financial Literacy dan Inovasi Pengrajin Logam Di Wilayah Kediri Raya. Diunduh pada tanggal 28/03/2016.

Lusardi. Annamaria dan Olivia S. Mitchell. (2007). Financial literacy and retirement preparedness: evidence and implications for Financial education program, Bussiness economic. Diunduh pada tanggal 26/03/2016.

MasterCard. (03 Juli 2013). Newzealenders Best at Money Management and Continue to Top The Index. http://bit.ly/lcLPC2l.

Monticone, Chiara. (2010). Financial Literacy and Financial Advice Theory and Empirical Evidence. Diunduh pada tanggal 19/04/2016.

Oseifuah, Emmanuel Kojo (2010). Financial Literacy and Youth Entrepreneurship in South Africa. Thohoyandou : Department of Accounting and Auditing University of Venda.

Rahmana, Arief (2009). Peranan Teknologi Informasi Dalam Peningkatan Daya Saing Usaha Kecil dan Menengah. Jurusan Teknik Industri, Fakultas Teknik,Universitas Widyatama. Diunduh pada tanggal 27/10/2016.

Rahmatia (2004). Kajian Teoritis dan Empiris Terhadap Pola dan Efisiensi. Konsumsi. Makassar: Fakultas Ekonomi UNHAS.

Riski Amaliyah, Rini Ssetyo Wati (2015). Analisis Faktor Yang Mempengaruhi Tingkat Literasi Keuangan Dikalangan UMKM Kota Tegal. Diunduh pada tanggal 19/12/2016.

Robb, C. A. dan James, R. N. (2009). Associations between individual characteristics and financial knowledge among college students. Journal of Personal Finance, 8, 170-184. Diunduh pada tanggal 27/04/2016.

Tasya Desiyana, (2015). Analisis Tingkat Literasi Keuangan Pada Pelaku Usaha Mikro Kecil dan Menengah Di Daerah Istimewa Yogyakarta. Diunduh pada tanggal 28/03/2016.

Volpe, R., Chen, H., dan Pavlicko, J., (1996). Personal Investment 
Literacy Among College Students, Financial Practice and Education, pp. 86-94.

Vincentius Andrew dan Nanik Linawati (2014). Hubungan Faktor
Demografi dan Pengetahuan

Keuangan Dengan Perilaku Keuangan Karyawan Swasta Di Surabaya. Diunduh pada tanggal 28/03/2015. 